\title{
Antioxidant Properties of Wild Edible Mushrooms
}

\author{
Ali Keleş ${ }^{1}$, İlkay Koca² and Hüseyin Gençcelep ${ }^{2 *}$
}

${ }^{1}$ Yüzüncü Yil University, Faculty of Education, Department of Biology Education, 65080 Van, Turkey

${ }^{2}$ Ondokuz Mayıs University, Faculty of Engineering, Department of Food Engineering, 55139 Samsun, Turkey

\begin{abstract}
The methanolic extracts of dried wild edible mushroom were analyzed for antioxidant activity in different assays, namely, ferric antioxidant reducing power (FRAP), scavenging activity on 1,1-diphenyl-2-picrylhydrazyl (DPPH) radicals and total phenolic content. Among the twenty four mushroom extracts, the methanolic extracts from Leccinum scabrum showed the most potent radical scavenging activity showing $97.96 \%$. The EC50 of Pleurotous dryinus and Lactarius piperatus methanolic extracts were 24.71 and $24.12 \mathrm{mg} / \mathrm{ml}$, respectively. Total phenolics in the methanolic extracts were the highest in Boletus edulis. On the other hand, dry matter and ascorbic acid were determined in twenty four dried wild edible mushrooms. The amounts of ascorbic acid and total phenolic compounds found in the mushroom extracts were determined very low concentrations. Results from the PCA showed that principal components (PC) 1 and 2 described about $79.588 \%$ of the total variation of sample. Therefore, edible mushrooms may have potential as natural antioxidants.
\end{abstract}

Keywords: Ascorbic acid; Total phenolic; Antioxidant activity; Wild edible mushroom

\section{Introduction}

Wild-growing mushrooms have a worldwide distribution and have been a popular delicacy in many countries. In fact, since ancient times mushrooms have been consumed by humans as a part of the normal diet and. They have a highly desirable taste and aroma, being also consumed for their texture: they add flavor and texture to a meal [1].

Mushrooms accumulate a variety of secondary metabolites, including phenolic compounds, polyketides, terpenes and steroids. Among the antioxidant compounds, polyphenols have gained importance due to their large array of biological actions that include free radical scavenging, metal chelation enzyme modulation activities and inhibition of LDL oxidation, among others [2,3]. The term polyphenol refers to a complex group of compounds that includes in their structure an aromatic ring bearing one or more hydroxyl groups. They comprise simple phenols such as phenolic acids and derivatives, as well as complex structures such as flavones, flavonoids or anthocyanins, among others [4-6].

Some common edible mushrooms have currently been found to possess antioxidant activity, which is well correlated with their total phenolic content [7]. Moreover, in the last few years, an increasing interest in the consumption of mushrooms has arisen, due to their elevated polyphenol concentration, which correlates with an elevated antioxidant activity. Several studies analyzing the total phenols and antioxidant activity of fresh and cooked wild and commercial mushrooms have been published [6,8-14]. However, as far as we know, characterization of species grown in different regions of Turkey has not been reported. The objective of this study was to evaluate the antioxidant properties of extracts from twenty four mushrooms from the East Blacksea region of Turkey. Their antioxidant activity was evaluated through the reducing power determination and radical scavenging activity of 2,2-diphenyl-1-picrylhydrazyl (DPPH) radicals. Bioactive compounds such as total phenolic content and ascorbic acid were also determined.

\section{Material and Methods}

\section{Material}

Twenty-four wild edible mushrooms samples were harvested from the East Black sea region of Turkey and were authenticated by Dr. Ali Keleş, Department of Biology, Faculty of Science and Arts, Yüzüncü Yıl University, Van, Turkey. Mushrooms as fruiting bodies (pileus + stipe) were dried at room temperature. They were stored at the Yüzüncü Yll University Faculty of Art and Science Microbiology Herbarium Laboratory.

Extract preparation: A fine dried mushroom powder (20 mesh) sample $(5 \mathrm{~g})$ was extracted with $80 \%$ of methanol $(50 \mathrm{~mL})$ for $24 \mathrm{~h}$ at 4 ${ }^{0} \mathrm{C}$. The mixture was vortexed (Vortex, DAIHAN VM-10 Vortex, SK) for $5 \mathrm{~min}$. Then, the extracts were filtered through Whatman No. 4 filter paper.

\section{Methods}

Dry matter: Dry matter content of dried mushroom was determined according to Association of Official Analytical Chemists methods [15]. The dry matter content was determined by drying in an oven at $105^{\circ} \mathrm{C}$ for $24 \mathrm{~h}$.

Ferric antioxidant reducing power (FRAP): Methanolic extracts were mixed with $0.95 \mathrm{ml}$ of ferric-TPTZ reagent (prepared by mixing $300 \mathrm{mM}$ acetate buffer, $\mathrm{p}^{\mathrm{H}}$ 3.6, $10 \mathrm{mM}$ TPTZ (2,4,6-tripyridyl-striazine, in $40 \mathrm{mM} \mathrm{HCl}$ and $20 \mathrm{mM} \mathrm{FeCl}_{3}$ in the ratio $10: 1: 1$ ), and absorbance was measured at $593 \mathrm{~nm}$. $\mathrm{FeSO}_{4}$ was used as a standard, and total antioxidant activity was expressed as $\mu \mathrm{mol} \mathrm{g} \mathrm{g}^{-1}$ FRAP [16].

*Corresponding author: Hüseyin Gençcelep, Ondokuz Mayıs University, Faculty of Engineering, Department of Food Engineering, 55139 Samsun, Turkey, Tel: +90 362 3121919; Fax: +90 362 4576094; E-mail: genccelep@hotmail.com

Received October 13, 2011; Accepted November 15, 2011; Published November 18,2011

Citation: Keleş A, Koca İ, Gençcelep H (2011) Antioxidant Properties of Wild Edible Mushrooms. J Food Process Technol 2:130. doi:10.4172/2157-7110.1000130

Copyright: @ 2011 Keleş A, et al. This is an open-access article distributed under the terms of the Creative Commons Attribution License, which permits unrestricted use, distribution, and reproduction in any medium, provided the original author and source are credited. 
Scavenging activity on 1,1-diphenyl-2-picrylhydrazyl (DPPH) radicals: The scavenging activity of the methanol extracts from mushrooms on DPPH radicals was measured according to the method of Nakajima et al. [17] with some modifications reported by Chiou et al. [18] $1 \mathrm{ml}$ of DPPH solution $\left(6 \times 10^{-5} \mathrm{M}\right.$ in methanol) was added to a test tube with $50 \mu \mathrm{L}$ of the diluted extracts (concentrations $2.5-50$ $\mathrm{mg} \mathrm{L}^{-1}$ ). Methanol was used instead of the mushroom sample as a control. The reaction mixture was vortex mixed at room temperature and the absorbance was measured after $30 \mathrm{~min}$ at $515 \mathrm{~nm}$ with a spectrophotometer. The obtained data were used to determine the quantity of mushrooms required to scavenge $50 \%$ of $\mathrm{DPPH}\left(\mathrm{EC}_{50}\right)$. The percent of reduction of DPPH was calculated according to the following equation:

$\% \mathrm{DPPH}$ reduction $=(\mathrm{Ac}-\mathrm{As} / \mathrm{Ac}) \times 100$.

Where;

As is the absorbance of sample after the time necessary to reach the plateau (30 $\mathrm{min}), \mathrm{A}_{\mathrm{c}}$ is the absorbance of control.

These values were plotted against quantity of mushrooms to obtain the mushrooms amount necessary to decrease the initial DPPH concentration by $50 \%\left(\mathrm{EC}_{50}\right)$ using an exponential curve.

Determination of antioxidant components: Total phenolic content was analyzed using Folin-Ciocalteu reagent [19]. Briefly, 0.5 $\mathrm{ml}$ of the extract was mixed with $1 \mathrm{ml}$ of Folin-Ciocalteu reagents. After $3 \mathrm{~min}, 1 \mathrm{ml}$ of saturated sodium carbonate solution was added to the mixture and it was adjusted to $10 \mathrm{ml}$ with distilled water. The reaction was kept in the dark for $60 \mathrm{~min}$, after which the absorbance was read at $760 \mathrm{~nm}$ a spectrophotometer. Gallic acid was used to calculate the standard curve (50-500 mg/mL). The results were expressed as $\mathrm{mg}$ of gallic acid (GAEs) equivalents per kg of extract.

Ascorbic acid content was determined using the 2,6-dichlorophenol-indophenol spectrophotometric method [20]. For ascorbic acid determination, the samples were extracted with metaphosphoric acid (4.5\%) for 6 hours at room temperature and filtered through Whatman No. 4 filter paper. The filtrate $(1 \mathrm{ml})$ was mixed with 2,6-dichlorophenolindophenol $(9 \mathrm{ml})$ and the absorbance was immediately measured at $520 \mathrm{~nm}$ against a blank. Content of ascorbic acid was calculated on the basis of the calibration curve of authentic L-ascorbic acid $(0.020-0.120 \mathrm{mg} / \mathrm{ml})$

\section{Statistical analysis}

The PCA was carried out of SPSS base 10.0 [21]. Varimax was applied in order to ensure that the resulting factors were uncorrelated.

\section{Results and Discussion}

\section{Ascorbic acid content}

Table 1 shows the ascorbic acid concentration in the mushroom extracts. The ascorbic acid was found in small amounts (n.d-249.33 mg/ $\mathrm{kg}$ ), which is in agreement with other authors [9]. This antioxidant was determined in different mushrooms but ascorbic acid was not detected in all mushrooms by spectrophotometry. Boletus pseudosulphureus extracts showed the highest ascorbic acid content $(249.33 \mathrm{mg} / \mathrm{kg}$ ); the amount found in Boletus edulis $(49,33 \mathrm{mg} / \mathrm{kg}$ ) was lower than the content found in Suillus luteus extracts $(82.67 \mathrm{mg} / \mathrm{kg})$. The highest content of ascorbic acid in the Boletus pseudosulphureus extracts might account for the better results found for their antioxidant activity. In fact, it had been reported that the antioxidant activity of plant materials is well correlated with the content of total phenolic content and ascorbic acid [22].

\section{Total phenolic content}

Total polyphenols were the major naturally occurring antioxidant components found in the methanolic extracts from wild edible mushrooms. The total phenolic content, expressed as $\mathrm{mg}$ of GAEs $/ \mathrm{kg}$ of dry mushroom, is shown in Table 1 . The amount of phenolic compounds in the methanol extracts from the two mushrooms (Boletus edulis and Boletus pseudosulphureus) was the highest (12775.56-11375.56 mg GAEs/kg of dry mushroom), respectively. Followed by Boletus erythropus and Macrolepiota procera (9931, 11-8886,67 mg GAEs/ $\mathrm{kg}$ of dry mushroom), respectively. By summation of the phenolic contents in the methanol solvent extracts, the total phenolic contents was $4020.0 \mathrm{~g}$ of GAEs/kg of dry mushroom for Hydnum repandum and $12775.33 \mathrm{mg}$ of GAEs/kg of dry mushroom for Boletus edulis (Table 1). Between the two mushrooms, the total phenolic content of Boletus edulis was almost thirty-three times higher than that of Hydnum repandum. The yield of total phenolic compounds extracted from these two mushrooms was higher than that obtained from Agaricus bisporus (5.40-0.85 mg of GAEs/kg dry mushroom) [23]. Also, total phenolic contens of ten muhrooms were higher than Agaricus bisporus (4020.0 $\mathrm{mg} / \mathrm{kg}$ ) in this study.

Phenols are important plant constituents because of their scavenging ability due to their hydroxyl groups [24]. The phenolic compounds may contribute directly to the antioxidative action [25]. In addition, it was reported that phenolic compounds were associated with antioxidant activity and play an important role in stabilizing lipid peroxidation [26]. The highest content of total phenols in the Boletus edulis and Boletus pseudosulphureus extracts might account for the better results found for their antioxidant activity. It had been reported that the antioxidant activity of plant materials was well correlated with the content of their phenolic compounds. Polyphenols, such as BHT (butylated hydroxytoluene) and gallate, are known to be effective antioxidants [22,27]. So, it is important to consider the effect of the total phenolic content on the antioxidant activity of mushroom extracts.

Ascorbic acid was found in small amounts (n.d-249.33 mg/kg) only six mushrooms in this study. Therefore, polyphenols/phenolics might be responsible for the antioxidant properties studied. The highest content of total polyphenols in Boletus edulis might be the key components accounting for the beter results found in antioxidant activity, reducing power, scavenging abilities as compared to other mushrooms. Generally, Boletus edulis was better in antioxidant activity, reducing power, and scavenging abilities and higher in the content of total polyphenols.

The phenolic compounds may contribute directly to antioxidative action [25]. It is suggested that polyphenolic compounds have inhibitory effects on mutagenesis and carcinogenesis in humans, when up to 1.0 $\mathrm{g}$ is ingested daily from a diet rich in fruits and vegetables [28]. Also, numerous studies have conclusively showed that consumption of foods high in phenolic content can reduce the risk of heart disease by slowing the progression of atherosclerosis, because they act as antioxidants $[27,29,30]$. Therefore, edible mushrooms may have potential as natural antioxidants in food.

This result indicates that polyphenols may be the main antioxidant compounds found in mushrooms, in agreement with several authors [12-14]. However it is important to evaluate the type of phenol present 
in mushroom and its individual contribution to the total antioxidant capacity. In this regards, studies are in progress evaluating other phenols and antioxidants present in mushrooms.

\section{Scavenging activity of DPPH radical}

Free radical scavenging is one of the mechanisms in inhibiting lipid oxidation commonly used to estimate antioxidant activity. The radical scavenging activity (RSA) of mushroom extracts was tested against the DPPH. DPPH, a stable free radical with a characteristic sorption at $515 \mathrm{~nm}$, was used to study the radical scavenging effects of extracts. As antioxidants donate protons to these radicals, the absorbance decreases. The decrease in absorbance is taken as a measure of the extent of radical-scavenging. Free radical-scavenging capacities of the tracts were measured by DPPH assay. Free radical scavenging is one of the known mechanisms by which antioxidants inhibit lipid oxidation. The method of scavenging DPPH free radicals can be used to evaluate the antioxidant activity of specific compounds or extracts in a short time. In Table 1, the scavenging activity of the DPPH radical due to its reduction by different mushrooms are illustrated.

The methanol extract of Suillus luteus and Boletus edulis showed the highest scavenging activity $(97.96,93.18 \%$ at $25 \mathrm{mg} / \mathrm{ml})$, respectively, but Hydnum repandum was much lower than that of all mushrooms in this study (10.17\%). Apparently, the scavenging abilities of Boletus ssp. They were found higher effectively than those of the other mushrooms in this study (Table 1).
The scavenging effects of methanolic extracts from mushroom species and standards on the DPPH radical decreased in the order of Lepista nuda, Russula delica, Polyporus squamosus, Pleurotus ostreatus, Agaricus bisporus, Verpa conica, Boletus badius and were, at the concentration of $180 \mathrm{mg} / \mathrm{mL}, 91.3,86.1,82.8,81.3,77.5,75.7$ and 68.7, respectively [6]. In this study, DPPH radical decreased in the order of Pleurotus ostreatus, Lepista nuda, Agaricus bisporus, Polyporus squamosus, Russula delica and were different from above study, at the concentration of $25 \mathrm{mg} / \mathrm{mL}, 86.35,85.61,67.86,43.30$ and 37.10 , respectively. Plant tissue antioxidant capacity is clearly associated with the activity of "free radical scavenging enzymes" (superoxide dismutase, catalase, peroxidase, etc.) and with the contents of antioxidant substances, mainly phenolic compounds, carotenoids, tocopherol and ascorbic acid. It is evident that there is an increasing demand to evaluate the antioxidant properties of direct plant extract [6].

Huang et al. [31] also found that the methanolic extract from Agaricus blazei showed a high scavenging ability of $97.1 \%$ at $2.5 \mathrm{mg} / \mathrm{ml}$. Tsai et al. [32] mentioned that the methanolic extract from Agrocybe cylindracea strain B scavenged DPPH radicals by $93.8 \%$ at $5 \mathrm{mg} / \mathrm{ml}$. Scavenging abilities of C. comatus were $84.5 \%$ at $5 \mathrm{mg} / \mathrm{ml}$ and $96.0 \%$ at $20 \mathrm{mg} / \mathrm{ml} \mathrm{[33]} \mathrm{and} \mathrm{P.} \mathrm{citrinopileatus} \mathrm{showed} \mathrm{a} \mathrm{scavenging} \mathrm{ability}$ of $94.9 \%$ at $5 \mathrm{mg} / \mathrm{ml}$ [34]. However, H. Marmoreus scavenged DPPH

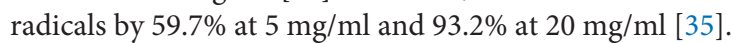

Obviously, the extracts contained antioxidant components, which

\begin{tabular}{|c|c|c|c|c|c|c|}
\hline & Dry matter, \% & $\begin{array}{c}\text { Ascorbic acid, } \\
\mathrm{mg} / \mathrm{kg}\end{array}$ & Total phenolics, mg/kg & $\mathrm{FRAP}, \mu \mathrm{mol} / \mathrm{g}$ & $\mathrm{DPPH}, \%^{1}$ & $\begin{array}{l}\mathrm{EC} 50 \\
\mathrm{mg} / \mathrm{ml}\end{array}$ \\
\hline Agaricus bisporus & 94.55 & n.d & 4020.00 & 12171.43 & 67.86 & 19.51 \\
\hline Chlororhyllum rhacodes & 93.75 & n.d & 4353.33 & 17885.71 & 80.64 & 11.18 \\
\hline Macrolepiota procera var. procera & 93.26 & n.d & 8886.67 & 7457.14 & 90.07 & 7.91 \\
\hline Amanita rubescens var. rubescens & 94.05 & 29.33 & 5708.89 & 31814.29 & 91.31 & 11.35 \\
\hline Pleurotous dryinus & 92.68 & 20.22 & 2353.33 & 11600.00 & 50.74 & 24.71 \\
\hline Armillaria ostoyae & 94.05 & $<20$ & 2908.89 & 5028.57 & 42.31 & - \\
\hline Pleurotous ostreatus & 93.20 & n.d & 2686.67 & 2385.71 & 86.35 & 11.07 \\
\hline Polyporus squamosus & 92.54 & $<20$ & 4531.11 & 2242.86 & 43.30 & - \\
\hline Boletus edulis & 93.53 & 49.33 & 12775.56 & 52957.14 & 93.18 & 3.95 \\
\hline Boletus pseudosulphureus & 95.17 & 249.33 & 11375.56 & 47528.57 & 90.82 & 7.88 \\
\hline Leccinum scabrum & 93.71 & n.d & 3175.56 & 23814.29 & 74.19 & 18.74 \\
\hline Suillus luteus & 93.85 & 82.67 & 5064.44 & 58528.57 & 97.96 & 4.76 \\
\hline Lepista nuda & 94.82 & n.d & 4175.56 & 12171.43 & 85.61 & 16.2 \\
\hline Lepista personata & 94.04 & n.d & 4220.00 & 8314.29 & 89.33 & 16.91 \\
\hline Hydnum repandum & 93.32 & n.d & 420.00 & 145.50 & 10.17 & - \\
\hline Lactarius deliciosus & 94.17 & $<20$ & 2708.89 & 2671.43 & 47.27 & - \\
\hline Lactarius piperatus & 92.13 & n.d & 3442.22 & 3528.57 & 52.60 & 24.12 \\
\hline Lactarius salmonicolor & 93.05 & 27.11 & 3242.22 & 4242.86 & 46.15 & - \\
\hline Lactarius volemus & 92.77 & $<20$ & 2331.11 & 3171.43 & 62.28 & 21.37 \\
\hline Russula delica & 95.18 & n.d & 2020.00 & 1160.00 & 37.10 & - \\
\hline Russula integra var.integra & 95.54 & n.d & 4508.89 & 1210.00 & 33.62 & - \\
\hline Russula nigricans & 93.89 & $<20$ & 4664.44 & 23600.00 & 78.16 & 19.40 \\
\hline Russula vinosa & 91.25 & n.d & 3064.44 & 1985.71 & 72.21 & 21.26 \\
\hline Boletus erythropus var. erythropus & 93.59 & n.d & 9931.11 & 62771.43 & 90.32 & 9.26 \\
\hline
\end{tabular}

n.d: not detected; ${ }^{1} 25 \mathrm{mg} / \mathrm{ml}$ reducing power,

Table 1: The results of dry matter and antioxidant capacity of wild edible mushrooms collected from the East Blacksea region of Turkey 
could react rapidly with DPPH radicals, and reduce most DPPH radical molecules. This result reveals that the extracts are a free radical inhibitor or scavenger, acting possibly as primary antioxidants. Various extracts might react with free radicals, particularly the peroxy radicals, which are the major propagators of the autoxidation chain of fat, thereby terminating the chain reaction [36-38]. Antioxidant activity of natural antioxidants has been shown to be involved in termination of free radical reaction [33]. These results indicated that methanolic extracts of mushroom species have a noticeable effect on scavenging free radical.

\section{Ferric antioxidant reducing power (FRAP)}

In the present work, antioxidant activity was measured by the FRAP method, which measures the capacity of an antioxidant to reduce a Fe ${ }^{3+}$-TPTZ complex to $\mathrm{Fe}^{2+}$-TPTZ. In this way, a higher $\mathrm{Fe}^{3+}$ -TPTZ reduction means a higher antioxidant activity. The reducing capacity of a compound may serve as a significant indicator of its potential antioxidant activity [39]. Table 1 indicates the reductive capabilities of methanolic extract of mushroom species. The extracts of Boletus erythropus var. erythropus possess the highest activity compared to other extracts. Among methanolic extracts from twenty four wild edible mushrooms, the reducing power of Boletus erythropus var. erythropus and Suillus luteus were 62771.43 and $58528.57 \mu \mathrm{mol} / \mathrm{g}$, respectively (Table 1). From the FRAP values of Boletus erythropus var. erythropus mushroom extracts in this study, it could be noted that Boletus erythropus var. erythropus had a higher reducing power due to the fact that it contained higher total phenolic content 21 mushrooms in all mushrooms (Table 1). When the antioxidant activity values of the wild mushrooms determined by the FRAP method where compared with other fruits, it was observed that mushrooms presented higher antioxidant activity than those reported for peaches, which ranged from 0.84 to $1.2 \mathrm{mmol} \mathrm{Fe} 2+/ 100 \mathrm{~g} \mathrm{FW}$, but lower than those for strawberries (19.3-24.4 mmol Fe2+/ 100 g DW) [40].

The antioxidant activity of putative antioxidants have been attributed to various mechanisms, among which are prevention of chain initiation, binding of transition metal ion catalysts, decomposition of peroxides, prevention of continued hydrogen abstraction, reductive capacity and radical scavenging [41-43].

\section{EC50}

The antioxidant properties assayed herein were summarized in Table 1 and the results were normalized and expressed as EC50 values (mg various extracts per $\mathrm{ml}$ ) for comparison. Effectiveness of antioxidant properties inversely correlated with their EC50 values. In Table 1, we present the EC50 values for reducing power and DPPH scavenging effects obtained from each mushroom methanolic extract.

Overall, Suillus luteus revealed better antioxidant properties than Lactarius piperatus (lower EC50 values), which is in agreement with the higher content of phenols found in the first species. This was much more evident in EC50 values for DPPH scavenging effect (4.76 mg/ $\mathrm{ml}$ for Suillus luteus versus $24.12 \mathrm{mg} / \mathrm{ml}$ for Lactarius piperatus). Searching wild sources may bring new natural products into the food industry with safer and better antioxidants that provide good protection against the oxidative damage, which occurs both in the body and our daily foods. Therefore, new wild edible mushrooms, as natural sources, could be introduced for this purpose. As far as our literature survey could ascertain, little information was available on the in vitro antioxidative activities of Turkey wild mushrooms.
EC50 values in scavenging ability on DPPH radicals were 4.76, 3.95, and $11.35 \mathrm{mg} / \mathrm{ml}$ for methanolic extracts from Suillus luteus, Boletus edulis and Amanita rubescens var. rubescens, respectively. Although Armillaria ostoyae, Polyporus squamosus, Hydnum repandum, Lactarius deliciosus, Lactarius salmonicolor, Russula delica and Russula integra var.integra were had DPPH, EC50 not found in this study.

It can be seen that EC50 values of all extracts were below $25 \mathrm{mg} /$ $\mathrm{ml}$ on the basis of dry sample in antioxidant properties assayed (Table 1). Although BHA and $\alpha$-tocopherol were good in inhibitory ability on lipid oxidation, reducing power and scavenging ability on DPPH radicals and EDTA was excellent for chelating ferrous ions, they are additives and used or present in mg levels in foods. However, Suillus luteus, Boletus edulis, Amanita rubescens var. rubescens, Boletus pseudosulphureus and Boletus erythropus var. erythropus could be used in $g$ levels as food or a food ingredient. Therefore, these mushrooms might serve as possible protective agents in human diets to help human reduce oxidative damage.

The results of PCA of the mean values of (total phenol, DPPH, FRAP and ascorbic acid) component 2 (EC50) of muhsroom samples are depicted in a 2-dimensional plot (Figure 1).

Results from the PCA showed that principal components (PC) 1 and 2 described about $79.588 \%$ of the total variation of sample: $54.820 \%$ PC1 and 24.768\% PC2. Principal component 1 was heavily loaded on total phenol, DPPH, FRAP and ascorbic acid, whereas component 2 was loaded on EC50. The PCA analysis showed that total phenol, DPPH, FRAP and ascorbic acid were positively correlated to each other., Results also showed that there is low significant relationship among total phenol, DPPH, FRAP, ascorbic acid and EC50 (Figure 1). In this study, no significant correlation was found between the amounts of EC50 and the total phenol, DPPH, FRAP and ascorbic acid in the mushroom samples in Figure 1. We found a high positive significant correlation between total phenol and FRAP.

A relationship between the reducing power and DPPH-scavenging activity was found, indicating that the mechanisms of action of the extracts for the antioxidant activity may be identical, being related to the content of total phenols. Though other antioxidants were probably present in these mushroom extracts, the amounts of ascorbic acid

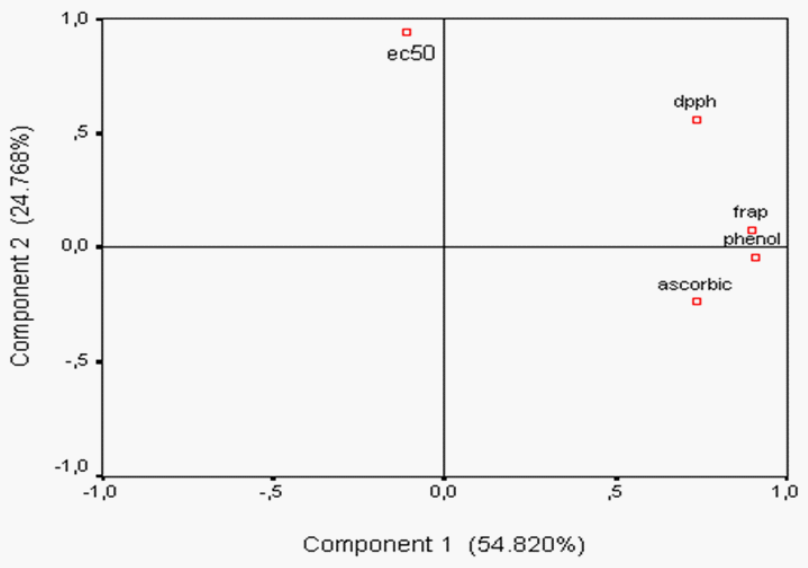

Figure 1: Principal component analysis biplot of total phenol, FRAP, ascorbic acid and EC50 of muhrooms. (DPPH= Scavenging activity on 1,1-diphenyl-2picrylhydrazyl radicals, FRAP= Ferric Antioxidant Reducing Power). 
found in this mushroom extracts were very low, which emphasises the idea that phenolic compounds could make a significant contribution to the mushrooms' antioxidant activity.

\section{Conclusions}

According to the results of this study, it is clearly indicated that the methanolic extract of mushroom species has significant antioxidant activity against various antioxidant systems in vitro; moreover, the mushroom species can be used as an easily accessible source of natural antioxidants and as a possible food supplement or in pharmaceutical industry. The various antioxidant mechanisms of the mushroom species extract may be attributed to strong hydrogen-donating ability, a metal-chelating ability, and their effectiveness as good scavengers of superoxide and free radicals. Phenolic compounds seem to be the main compenents responsible for the antioxidant activity of all the mushroom species extracts. From the wild mushrooms studied, Boletus may be an interesting group due to their high total phenol concentration, antioxidant activity and ascorbic acid. In general, a correlation between higher antioxidant activity and larger amount of total phenolics was found in the mushroom extracts. Though other antioxidants were probably present in these mushroom extracts, total phenolic compounds could make a significant contribution to the antioxidant activity in these extracts. Having established the antioxidant activity in these mushroom extracts, the chemical characteristics of the antioxidative components in these extracts will be further investigated. It revealed that in addition to these antioxidant activities, other factors contribute in part to the antioxidant properties of wild edible mushrooms. It is recommended Boletus for use in foods as natural antioxidants or extracts. To study the antioxidant mechanisms by some other potential antioxidant components, the fractionation of the methanolic extract and further identification are in progress.

\section{References}

1. Valentáo P, Lopes G, Valente M, Barbosa P, Andrade PB, et al. (2005) Quantitation of Nine Organic Acids in Wild Mushrooms. J Agric Food Chem 53: 3626-3630.

2. Teissedre PL, Landrault N (2000) Wine phenolics: contribution to dietary intake and bioavailability. Food Res Int 33: 461-467.

3. Rodrigo R, Bosco C (2006) Oxidative stress and protective effects of polyphenols: comparative studies in human and rodent kidney. A review. Comp Biochem Physiol Part C Toxicol Pharmacol 142: 317-327.

4. Isıldak O, Turkekul I, Elmastaş M, Tüzen M (2004) Analysis of heavy metals in some wild-grown edible mushrooms from the middle black sea region, Turkey. Food Chem 86: 547-552.

5. Türkekul I, Elmastaş M, Tüzen M (2004) Determination of iron, copper, manganese, zinc, lead, and cadmium in mushroom samples from Tokat, Turkey. Food Chem 84: 389-392.

6. Elmastas M, Isıldak O, Turkekul I, Temur N (2007) Determination of antioxidant activity and compounds in wild edible mushrooms. J Food Compost Anal 20: 337-345

7. Barros L, Ferreira MJ, Queirơs B, Ferreira ICFR, Baptista P (2007) Total phenols, ascorbic acid, $\beta$-carotene and lycopene in Portuguese wild edible mushrooms and their antioxidant activities. Food Chem 103: 413-419.

8. Mau JL, Chao GR, Wu KT (2001) Antioxidant properties of methanolic extracts from several ear mushrooms J Agric Food Chem 49: 5461-5467.

9. Mau JL, Lin HC, Song SF (2002) Antioxidant properties of several specialty mushrooms. Food Res Int 35: 519-526.

10. Yang JH, Lin HC, Mau JL (2002) Antioxidant properties of several commercial mushrooms Food Chem 77: 229-235.

11. Lakshmi B, Tilak JC, Adhikari S, Decasagayam TPA, Janardhanan KK (2004)
Avaluation of antioxidant activity of selected indian mushrooms. Pharmaceutical Biol 42: 179-185.

12. Lo KM, Cheung PCK (2005) Antioxidant activity of extracts from the fruiting bodies of Agrocybe aegerita var. Alba Food Chem 89: 533-539.

13. Choi Y, Lee SM, Chun J, Lee HB, Lee J (2006) Influence of heat treatment on the antioxidant activities and polyphenolic compounds of Shiitake (Lentinus edodes) mushroom. Food Chem 99: 381-387.

14. Ferreira ICFR, Baptista P, Vilas-Boas M, Barros L (2007) Free-radical scavenging capacity and reducing power of wild edible mushrooms from northeast Portugal: Individual cap and stipe activity Food Chem 100: 1511 1516.

15. AOAC (2000) Official Methods of Analysis of the Association of Official Analysis Chemists (17th edn), AOAC International, Gaithersburg, MD.

16. Gao X, Björk L, Trajkovski V, Uggla M (2000) Evalution of antioxidant activies of rosehip ethanol extracts in different test systems. J Sci Food Agric 80: 2021 2027.

17. Nakajima JI, Tanaka I, Seo S, Yamazaki M, Saito K (2004) LC/PDA/ESI-MS profiling and radical scavenging activity of anthocyanins in various berries. $J$ Biomed Biotechnol 5: 241-247.

18. Chiou A, Karathanos VT, Mylona A, Salta FN, Preventi F, et al. (2007) Currants (Vitis vinifera L.) content of simple phenolicsand antioxidant activity. Food Chem102: 516-522.

19. Singleton VL, Rossi JA (1965) Colorimetry of total phenolics with phosphomolybdic-phosphotungstic acid reagents. Am J Enol Vitic 16: 144-158.

20. Regnell CJ (1976) The analytical methods of processed fruit and vegetable Publication of Food Control Education and Research Institute of Bursa 2: 91 92.

21. SPSS, Base User's Guide (2000) 10.0 SPSS for Windovs 98.Chicago, USA

22. Velioglu YS, Mazza G, Gao L, Oomah BD (1998) Antioxidant activity and tota phenolics in selected fruits, vegetables, and grain products. J Agric Food Chem 46: $4113-4117$

23. Choi SW, Sapers GM (1994) Effects of washing on polyphenols and polyphenol oxidase in commercial mushrooms (Agricus bisporus). J Agric Food Chem 42 2286-2290.

24. Hatano T, Edamatsu R, Mori A, Fujita Y, Yasuhara E (1989) Effect of interaction of tannins with co-existing substances. VI. Effects of tannins and related polyphenols on superoxide anion radical and on DPPH radical. Chemical and Pharmaceutical Bulletin 37: 2016-2021.

25. Duh PD, Tu YY, Yen GC (1999) Antioxidant activity of water extract of harn jyur (Chyrsanthemum morifolium Ramat). Lebensmittel-Wissenschaft und Technologie 32: 269-277.

26. Yen GC, Duh PD, Tsai CL (1993) Relationship between antioxidant activity and maturity of peanut hulls. J Agric Food Chem 41: 67-70

27. Halliwell B, Gutteridge JMC (2003) Free Radicals in Biology and Medicine. Oxford University Press, Oxford, UK.

28. Tanaka, Kuei CW, Nagashima Y, Taguchi T (1998) Application of antioxidative maillrad reaction products from histidine and glucose to sardine products. Nippon Suisan Gakkaishil 54: 1409-1414.

29. Kaur C, Kapoor HC (2002) Anti-oxidant activity and total phenolic content of some Asian vegetables. International J Food Sci Technol 37: 153-161.

30. Kahkonen MP, Hopia AI, Vuorela HJ, Raucha JP, Pihlaja K, et al. (1999) Antioxidant activity of plant extracts containing phenolic compounds. J Agric Food Chem 47: 3954-3962.

31. Huang SJ, Huang LC, Chen CC, Mau JL (1999) Antioxidant properties of Agaricus blazei. In: Broderick, A., Nair, T. (Eds.), Proceedings of the third international conference on mushroom biology and mushroom products (266274), Sydney, Australia.

32. Tsai SY, Huang SJ, Mau JL (2006) Antioxidant properties of hot water extracts from Agrocybe cylindracea. Food Chem 98: 670-677. 
Citation: Keleş A, Koca İ, Gençcelep H (2011) Antioxidant Properties of Wild Edible Mushrooms. J Food Process Technol 2:130. doi:10.4172/21577110.1000130

Page 6 of 6

33. Tsai SY, Tsai HL, Mau JL (2007) Antioxidant properties of Agaricus blazei, Agrocybe cylindracea, and Boletus edulis. LWT-Food Sci Technol 40: 13921402.

34. Lee YL, Huang GW, Liang ZC, Mau JL (2007) Antioxidant properties of three extracts from Pleurotus citrinopileatus. LWT-Food Sci Technol 40: 823-833.

35. Lee YL, Yen MT, Mau JL (2007) Antioxidant properties of various extracts from Hypsizigus marmoreus. Food Chem 104: 1-9.

36. Frankel EN (1991) Recent advances in lipid oxidation. J Sci Food Agric 54: 495-511.

37. Shahidi F, Wanasundara PKJPD (1992) Phenolic antioxidants. Critical Reviews in Food Science and Nutrition 32: 67-103.

38. Brand-Williams W, Cuvelier ME, Berset C (1995) Use of a free radical method to evaluate antioxidant activity. LWT-Food Sci Technol 28: 25-30.
39. Meir S, Kanner J, Akiri B, Hadas SP (1995) Determination and involvement of aqueous reducing compounds in oxidative defence systems of various senescing leaves. J Agric Food Chem 43: 1813-1819.

40. Alvarez-Parrilla E, de la Rosa LA, Martinez NR, Gonzalez-Aguilar GA (2007) Total Phenols and Antioxident Activity of Commercial and Wild Mushrooms from Chiuahua, Mexico. Ciencia Y Tecnologia Alimentaria 5: 329-334.

41. Diplock AT (1997) Will the 'good fairies' please proves to us that vitamin $E$ lessens human degenerative of disease? Free Radic Res 27: 511-532.

42. Gulçin I, Buyukokuroglu ME, Oktay M, Kufrevioglu OI (2002) On the in vitro antioxidant properties of melatonin. Journal of Pineal Research 33: 167-171.

43. Gulçin I, Oktay M, Kufrevioglu OI, Aslan A (2002) Determination of antioxidant activity of lichen Cetraria islandica (L) Ach. J Ethnopharmacol 79: 325-329. 